\title{
Pendugaan Umur Simpan Bubuk Kopi Arabika Menggunakan Metode Arrhenius dengan Kemasan Aluminium Foil dan Plastik (Polipropilen)
}

\author{
The Shelf Life Prediction of Arabica Coffee Powder Using \\ Arrhenius Method with Aluminum Foil and Plastic (Polypropylene) \\ Packaging
}

\author{
Elida Novita $^{1 \bowtie}$, Dian Purbasari ${ }^{1}$, M. Syahrul Munir Mubarok ${ }^{1}$ \\ ${ }^{1}$ Jurusan Teknik Pertanian, Fakultas Teknologi Pertanian, Universitas Jember \\ ${ }^{\bowtie}$ Komunikasi Penulis, email: elida_novita.ftp@unej.ac.id \\ DOI:http://dx.doi.org/10.23960/jtep-lv10i3.392-401 \\ Naskah ini diterima pada 30 Mei 2021; revisi pada 16 September 2021; \\ disetujui untuk dipublikasikan pada 18 September 2021
}

\begin{abstract}
The storage method is one way to maintain coffee quality. Storage with aluminum foil and plastic (PP) packaging is an effective and safe technology to protect coffee grounds. Specialty coffee powder cannot be accepted if the organoleptic score is below 80, for that it is necessary to estimate the shelf life. This study aims to analyze the quality degradation of Bondowoso arabica coffee powder based on specialty standards using the SCAA protocol during storage with aluminum foil packaging and compare it with plastic packaging (PP) and estimated the shelf life of Bondowoso arabica ground coffee products based on flavor value parameters using the arrhenius method. Coffee powder quality degradation with plastic packaging (PP) is faster than aluminum foil packaging. This is because plastic packaging on the fourth day with a temperature of $40^{\circ} \mathrm{C}$ is not meet specialty standards. The greater the temperature used, the greater the decrease in quality. The shelf life of coffee powder uses aluminum foil packaging, which is 3 days at $40^{\circ} \mathrm{C}, 2$ days at $50^{\circ} \mathrm{C}$, and 1.3 days at $60^{\circ} \mathrm{C}$. Whereas with plastic packaging $(P P)$, the shelf life is shorter, which is 2 days at $40^{\circ} \mathrm{C}, 1.2$ days at $50^{\circ} \mathrm{C}$ and 1 day at $60^{\circ} \mathrm{C}$.
\end{abstract}

Keyword : accelerated Shelf-Life Testing (ASLT), aluminum foil, arabica coffee, packaging, shelf life

\begin{abstract}
ABSTRAK
Metode penyimpanan merupakan salah satu cara untuk mempertahankan mutu kopi. Penyimpanan dengan kemasan aluminium foil dan plastik (PP) merupakan teknologi yang efektif dan aman untuk melindungi bubuk kopi. Bubuk kopi spesialti tidak dapat diterima apabila nilai cita rasanya sudah di bawah angka 80, untuk itu perlu dilakukan pendugaan umur simpan. Penelitian ini bertujuan untuk menganalisis penurunan mutu bubuk kopi arabika Bondowoso berdasarkan standar spesialti menggunakan SCAA protokol selama penyimpanan dengan kemasan aluminium foil dan membandingkannya dengan kemasan plastik (PP) dan melakukan pendugaan umur simpan produk kopi bubuk arabika Bondowoso berdasarkan parameter nilai cita rasa dengan menggunakan metode arrhenius. Penurunan mutu bubuk kopi dengan kemasan plastik (PP) lebih cepat daripada kemasan alumunium foil. Hal ini dikarenakan kemasan plastik pada hari keempat dengan suhu $40^{\circ} \mathrm{C}$ sudah tidak masuk standar spesialti. Semakin besar suhu yang digunakan maka penurunan mutu akan semakin besar. Umur simpan bubuk kopi menggunakan kemasan aluminium foil yaitu 3 hari pada suhu $40^{\circ} \mathrm{C}, 2$ hari pada suhu $50^{\circ} \mathrm{C}$ dan 1,3 hari pada suhu $60^{\circ} \mathrm{C}$. Sedangkan dengan kemasan plastik (PP) umur simpannya menjadi lebih singkat yaitu 2 hari pada suhu $40^{\circ} \mathrm{C}, 1,2$ hari pada suhu $50^{\circ} \mathrm{C}$ dan 1 hari pada suhu $60^{\circ} \mathrm{C}$.
\end{abstract}

Kata kunci : aluminium foil, ASLT, kopi arabika, pengemasan, umur simpan

\section{PENDAHULUAN}

Menurut International Coffee Organization (2013), Indonesia menjadi negara keempat penghasil kopi terbesar dunia. Kopi Indonesia khususnya arabika Bondowoso memiliki cita rasa yang khas dan banyak diminati konsumen. Merujuk data Direktorat Jenderal Perkebunan (2017), Kabupaten Bondowoso memiliki luas lahan sebesar $36.012 \mathrm{Ha}$ dan $12.798 \mathrm{Ha}$ di 
antaranya merupakan lahan perkebunan kopi. Sehingga komoditas utama di Bondowoso yaitu kopi. Produksi kopi arabika Bondowoso pada tahun 2016 sebesar 5,157 ton (Badan Pusat Statistik, 2019). Agroindustri Kopi Wulan merupakan salah satu agroindustri kopi di Kabupaten Bondowoso yang memproduksi kopi Arabika melalui pengolahan semi basah dan berpotensi memperoleh sertifikasi Indikasi Geografis (IG) (Novita et al. 2021).

Menurut Ati \& Nursamsiyah (2015), kopi arabika merupakan salah satu jenis kopi yang memiliki kualitas cita rasa tinggi dan kadar kafein lebih rendah dibandingkan kopi robusta sehingga kopi arabika banyak diminati konsumen. Kopi memiliki periode pemanenan selama 2 sampai dengan 3 bulan sehingga kopi harus disimpan agar tersedia sepanjang tahun. Metode penyimpanan merupakan salah satu cara untuk mempertahankan mutu kopi (Hakim, 2017). Adapun faktor yang dapat mempengaruhi mutu kopi selama penyimpanan yaitu suhu dan jenis kemasan yang digunakan (Andayani dan Agustini, 2019; Tarigan et al. 2021).

Bahan pengemas produk kopi harus memiliki sifat permeabilitas yang rendah terhadap uap air dan oksigen seperti jenis kemasan berbahan aluminium foil dan plastik (PP) (Aprida et al, 2017). Jenis kemasan dan suhu penyimpanan yang digunakan berpengaruh pada mutu kopi dan umur simpannya. Sejalan dengan pernyataan tersebut Specialty Coffee Association of America (2015), bubuk kopi yang tidak masuk dalam standar kopi spesialti (specialty grade) yaitu bubuk kopi yang nilai cita rasanya sudah kurang dari 80. Penilaian tentang umur simpan dapat dilakukan pada kondisi dipercepat (accelerated shelf life test) yang selanjutnya dapat memprediksi umur simpan yang sebenarnya. Metode ini dapat dilakukan dengan mengkondisikan bahan pangan pada suhu dan kelembaban relatif yang tinggi sehingga titik kritis lebih cepat tercapai. Penentuan umur simpan dengan metode Arrhenius termasuk kedalam metode akselerasi ini. Mengingat pentingnya umur simpan dengan tingkat akurasi tinggi maka perlu dilakukan pendugaan umur simpan pada bubuk kopi menggunakan metode Arrhenius berdasarkan nilai cita rasa yang masuk standar spesialti.
Penelitian ini memiliki tujuan umum yaitu menganalisis penurunan mutu bubuk kopi arabika Bondowoso berdasarkan standar spesialti menggunakan protokol SCAA selama penyimpanan dengan menggunakan 2 kemasan berbeda yaitu aluminium foil dan plastik (PP). Selanjutnya melakukan pendugaan umur simpan bubuk kopi arabika Bondowoso berdasarkan parameter nilai cita rasa dengan ASLT metode Arrhenius.

\section{BAHAN DAN METODE}

Penelitian ini dilaksanakan pada bulan September sampai Oktober 2019 di Desa Tanah Wulan, Kecamatan Maesan, Kabupaten Bondowoso dan Kafe Macro di Jl. Mastrip Timur 110b, Kecamatan Sumbersari, Kabupaten Jember, serta di Laboratorium Enjiniring Hasil Pertanian, Jurusan Teknik Pertanian, Fakultas Teknologi Pertanian, Universitas Jember.

Alat yang digunakan pada penelitian ini meliputi oven dengan tipe Selecta, oven dengan tipe Konka, oven dengan tipe Daeyang ET5, neraca analitik, kemasan plastik (PP) 100 gr, kemasan aluminium foil $100 \mathrm{gr}$, mesin sangrai kopi dengan tipe burner gas $3 \mathrm{~kg}$, Mesin giling pembuat bubuk kopi dengan tipe no: FFC-15, mangkuk keramik sup $250 \mathrm{~mL}$, sendok cupping spoon sc001 stainless steel, thermocouple thermometers, impuls sealer, dan teko stainless steel. Bahan utama yang digunakan pada penelitian ini adalah biji kopi (green bean) arabika Bondowoso. Biji kopi diolah secara basah yaitu biji kopi setelah dipanen dilakukan pencucian dan pengupasan kulit buah, kemudian di fermentasi selama 36 jam. Selanjutnya biji kopi dibilas dan dijemur sampai kadar air 30-35\%. Biji kopi digiling untuk mengupas kulit tanduk dan dijemur lagi sampai kadar air $11-12 \%$.

\subsection{Persiapan Sampel}

Sampel bubuk kopi yang digunakan sebanyak 2 $\mathrm{kg}$ (diberi perlakuan) dan 300 gram (kontrol), selanjutnya dikemas sebanyak 100 gram ke dalam setiap kemasan alumunium foil dan kemasan plastik (pp). Total kemasan yang dihasilkan yaitu 10 kemasan alumunium foil dan 10 kemasan plastik (pp). Secara garis besar bisa dibagi menjadi 3 bagian utama yaitu persiapan 
sampel, evaluasi sensoris, dan penilaian Proses persiapan sampel terdiri dari proses sangrai (roasting), penggilingan (grinding), dan penyeduhan (brewing). Pada proses sangrai terdapat $3 \mathrm{~kg}$ sampel kopi (green bean) disangrai menggunakan mesin sangrai tipe burner gas 3 $\mathrm{kg}$ dengan tingkat sangrai medium (level roast medium) dengan suhu $180^{\circ} \mathrm{C}$ selama $45-50$ menit (Sutarsi et al. 2016). Setelah itu biji kopi sangrai (roasted bean) didiamkan terlebih dahulu selama minimal 8 jam, kemudian digiling menggunakan mesin giling pembuat bubuk kopi dengan tipe no: FFC-15.

\subsection{Penentuan Nilai Cita Rasa Bubuk Kopi dengan Metode Cupping}

Penentuan nilai citarasa kopi dilakukan dengan metode cupping yang mengacu pada protokol cupping Specialty Coffee Association of America atau SCAA protokol. Sebanyak $8.25 \mathrm{~g}$ bubuk kopi dan ditempatkan dalam wadah mangkuk keramik. Sampel yang digunakan sudah diberikan kode pada setiap kemasan sehingga panelis tidak mengeteahui sampel tersebut (Specialty Coffee Association of America, 2015).

Panelis menilai aroma bubuk kopi dengan indera penciuman, kemudian kopi diseduh menggunakan air $150 \mathrm{ml}$ bersuhu $93^{\circ} \mathrm{C}$ dan didiamkan selama 3-5 menit. Satu jenis sampel bubuk kopi memerlukan 5 kali pengulangan atau dengan kata lain membutuhkan 5 mangkuk (wadah) setiap pengujian. Tahap selanjutnya adalah evaluasi sensori yang dilakukan oleh 3 panelis atau Q-grader. Kopi yang sudah diseduh selama 3 sampai 5 menit tadi diaduk menggunakan sendok cupping (Specialty Coffee Association of America, 2015).

Menurut Specialty Coffee Association of America (2015), kualifikasi kopi berdasarkan skor akhir yang dibagi ke dalam 4 kategori, yaitu 3 kategori kopi spesialti dengan klasifikasi outstanding (90-100), excellent (85-89,99), dan very good (80-84,99), dan 1 kategori bukan kopi spesialti (di bawah 80). Kopi dengan kategori outstanding, excellent, dan very good atau dengan skor akhir 80 sampai 100 masuk ke dalam kualifikasi kopi spesialti dan kopi dengan nilai skor akhir di bawah 80 masuk ke dalam kualifikasi kopi bukan spesialti namun masih layak dikonsumsi.

\subsection{Percobaan Percepatan Penurunan Mutu dan Analisis Penurunan Nilai Cita Rasa Kopi Selama Penyimpanan}

Prosedur pengamatan percobaan penurunan mutu bubuk kopi selama penyimpanan yaitu sampel bubuk kopi dikemas menggunakan kemasan berbeda, yaitu dengan kemasan alumunium foil dan kemasan plastik (PP). Masing-masing kemasan diisi dengan $100 \mathrm{~g}$ sampel bubuk kopi kemudian disimpan pada oven dengan tiga level suhu yaitu suhu $40^{\circ} \mathrm{C}$, $50^{\circ} \mathrm{C}$, dan $60^{\circ} \mathrm{C}$. Sampel ada 30 kemasan untuk masing-masing suhu penyimpanan, yaitu 5 kemasan menggunakan kemasan aluminum foil dan 5 kemasan lagi menggunakan kemasan plastik (PP) (Hakim, 2017). Penelitian pada tahap ini adalah melakukan analisis terhadap perubahan mutu bubuk kopi khususnya nilai cita rasa kopi selama disimpan dengan perlakuan suhu masing-masing.

\subsection{Pendugaan Umur Simpan dengan Pendekatan Arrhenius}

Metode analisis pendugaan umur simpan dilakukan dengan melakukan pengujian terhadap nilai cita rasa kopi, pengujian dilakukan sampai nilai cita rasa kopi di bawah nilai 80 atau sampai didapatkan trendline pada grafik antara nilai cita rasa dan waktu penyimpanan, dengan pengambilan sampel dilakukan setiap 2 hari selama 8 hari penyimpanan untuk semua suhu penyimpanan. Rentang waktu pengambilan sampel ini dilakukan berdasarkan penelitian pendahuluan, di mana sampel kopi mulai terlihat perubahannya pada hari kedua penyimpanan (Arpah, 2001).

Parameter nilai cita rasa bubuk kopi dimasukkan ke dalam grafik hubungan antara waktu penyimpanan (hari) dengan rata-rata penurunan nilai cita rasa. Sumbu X menunjukkan waktu penyimpanan (hari) dan sumbu Y menunjukkan rata-rata penurunan nilai cita rasa kopi yang dapat dilihat pada Gambar 1 .

Setelah dibuat grafik untuk masing-masing suhu penyimpanan, selanjutnya akan dicari nilai regresi linier dari masing-masing grafik tersebut. Gradient dari regresi linier grafik tersebut merupakan nilai k (nilai b1 pada grafik atau Gambar 1) nilai k ini akan dimasukkan ke dalam grafik Arrhenius sebagai ln k. Setelah itu dibuat 


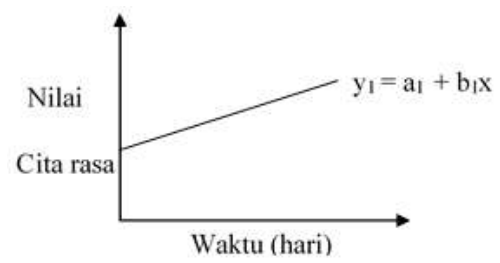

Gambar 1. Grafik Hubungan Antara Waktu Penyimpanan (Hari) dengan Rata-rata Penurunan Mutu Parameter Kritis/Hari (Sumber : Arpah, 2001)

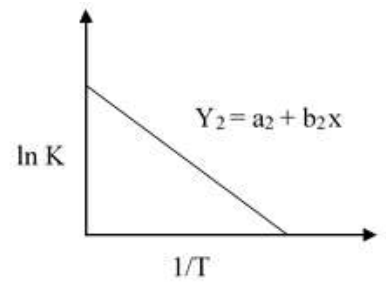

Gambar 2. Grafik Hubungan Nilai ln K dan 1/T dengan slope (-Ea/RT) pada Persamaan Arrhenius (Sumber : Arpah, 2001)

grafik Arrhenius, sumbu X menyatakan 1/T ( $\mathrm{T}$ merupakan suhu penyimpanan yang digunakan dalam satuan Kelvin) dan sumbu Y menyatakan ln $\mathrm{k}$, contoh grafik dapat dilihat pada Gambar 2. Setelah didapatkan nilai $-\mathrm{Ea} / \mathrm{R}$ dan $\mathrm{K} 0$ selanjutnya akan dicari nilai laju penurunan mutu (K) untuk masing-masing suhu penyimpanan menggunakan persamaan Arrhenius (Arpah, 2001). Formula tersebut dapat dilihat pada Persamaan 1 dan 2.

$$
\mathrm{K}=\mathrm{K}_{0} \cdot \mathrm{e}^{-\mathrm{Ea} / \mathrm{RT}}
$$

dimana K adalah konstanta laju reaksi pada suhu $\mathrm{T}, \mathrm{K}_{0}$ adalah konstanta pre-eksponensial, Ea adalah energi aktivasi (kal/mol), T adalah suhu mutlak (K), dan $\mathrm{R}$ adalah konstanta gas $(1,986$ $\mathrm{kal} / \mathrm{mol} \mathrm{K}$ ).

$$
\mathrm{t}=\frac{\mathrm{A}_{0}-\mathrm{A}}{\mathrm{K}_{0} \cdot \mathrm{e}^{-\mathrm{E} / \mathrm{RT}}}
$$

dimana t adalah prediksi umur simpan (hari), $\mathrm{A} 0$ adalah nilai mutu awal, dan A adalah nilai mutu produk yang tersisa setelah waktu $(\mathrm{t})$.

\section{HASIL DAN PEMBAHASAN}

\subsection{Analisis Cita Rasa Awal Bubuk Kopi}

Penentuan nilai awal atau tanpa perlakuan dari citarasa bubuk kopi Arabika mendapat total nilai skor cita rasa sebesar 87,00 sehingga kopi ini termasuk dalam kategori kopi spesialti. Hal ini dikarenakan nilai total skor cita rasa lebih dari
80. Hasil dari sampel nilai awal ini dapat dilihat pada Tabel 1.

Berdasarkan Tabel 1, nilai 10 pada atribut uniformity, cleancup dan sweetness menunjukan tidak adanya rasa dan nilai negatif dari beberapa parameter sehingga keseragaman nilai kopi pada parameter ini akan semakin tinggi. Kriteria penilaian ini harus memperhatikan mulai dari kopi pertama masuk mulut sampai akhirnya ditelan atau dibuang (Specialty Coffee Association of America, 2015).

\subsection{Analisis Penurunan Mutu dan Nilai Cita Rasa Selama Penyimpanan}

Pengujian nilai cita rasa dilakukan setiap dua hari sekali yaitu pada hari kedua, keempat, keenam, dan kedelapan penyimpanan (Tabel 2). Menurut Hakim (2017), perubahan nilai pada atribut citarasa kopi terlihat signifikan pada rentang dua hari penyimpanan.

\subsection{Simulasi Nilai Cita Rasa dengan Waktu Penyimpanan}

Hasil simulasi ditampilkan dengan grafik antara nilai cita rasa kopi dan waktu penyimpanan (hari) berdasarkan suhu penyimpanan dan jenis kemasan yang dapat dilihat pada Gambar 3 dan 4. Berdasarkan hasil yang didapat, bubuk kopi yang disimpan pada suhu tinggi mengalami penurunan mutu lebih cepat dibandingkan bubuk kopi yang disimpan pada suhu rendah. Berdasarkan hasil kajian yang dilakukan oleh 
Tabel 1. Nilai Cita Rasa Awal Kopi Bubuk Arabika

\begin{tabular}{lc}
\hline \multicolumn{1}{c}{ Attribute } & Score \\
\hline Fragrance/Aroma & 8,5 \\
Flavor & 8,25 \\
Aftertase & 8 \\
Acidity & 8 \\
Body & 8,25 \\
Uniformity & 10 \\
Balance & 8 \\
Cleancup & 10 \\
Sweetness & 10 \\
\hline Overall & $\mathbf{8}$ \\
\hline Total Score & $\mathbf{8 7 , 0 0}$ \\
\hline
\end{tabular}

Sumber : Analisis data, 2019

Tabel 2. Penurunan Nilai Cita Rasa Selama Penyimpanan dengan Kemasan Alumunium Foil (AF) dan Plastik (PP)

\begin{tabular}{|c|c|c|c|c|c|c|}
\hline \multirow{3}{*}{ Hari ke- } & \multicolumn{6}{|c|}{ Nilai Cita Rasa } \\
\hline & \multicolumn{2}{|c|}{$40^{\circ} \mathrm{C}$} & \multicolumn{2}{|c|}{$50^{\circ} \mathrm{C}$} & \multicolumn{2}{|c|}{$60^{\circ} \mathrm{C}$} \\
\hline & AL & PP & $\mathrm{AL}$ & PP & $\mathrm{AL}$ & PP \\
\hline 0 & 87,00 & 87,00 & 87,00 & 87,00 & 87,00 & 87,00 \\
\hline 2 & 84,92 & 84,42 & 83,75 & 83,00 & 81,00 & 80,83 \\
\hline 4 & 83,33 & 79,33 & 82,00 & 77,67 & 75,00 & 74,42 \\
\hline 6 & 81,50 & 74,42 & 80,33 & 72,92 & 70,75 & 67,00 \\
\hline 8 & 75,25 & 68,25 & 73,17 & 67,33 & 61,67 & 51,00 \\
\hline
\end{tabular}

Keterangan $: \mathrm{AL}=$ kemasan aluminium foil; $\mathrm{PP}=$ kemasan plastik (pp) (Sumber : Analisis data, 2019)

Labuza et al. (1985), suhu akan berpengaruh pada kerusakan bahan dan kecepatan reaksi yang meningkat akan mempengaruhi kualitas bahan. Menurut Hakim (2017), penyimpanan pada suhu yang tinggi akan mempercepat terjadinya reaksi pada bahan pangan sehingga migrasi zat perusak kualitas pangan semakin besar. Selain itu kopi yang disimpan dengan kemasan alumunium foil mengalami penurunan mutu lebih lambat dibandingkan kemasan plastik (PP). Kopi menjadi rusak karena suhu panas (oven). Adanya aluminium membuat panas sebagian sulit masuk tertahan bahan kemasan sehingga laju kerusakan kopi menjadi lebih lambat.

\subsection{Verifikasi Nilai Kemasan}

Perbandingan pada penelitian ini yaitu nilai kemasan alumunium foil dengan kemasan plastik (PP). Parameter statistik yang digunakan yaitu nilai RMSE (root mean square error), untuk mengevaluasi nilai kemasan alumunium foil dan plastik (PP) (Wardana dan Timur, 2018). Merujuk pada Tabel 3, nilai kemasan alumunium foil dengan plastik (PP) menggunakan RMSE yaitu bernilai 1,25 . Jika diubah dalam bentuk persentase maka nilai RMSE dibagi 5 dan dikalikan dengan 100 (Wardana dan Timur (2018). Sehingga didapatkan nilai eror sebesar $25,02 \%$ atau dapat dikatakan bahwa akurasinya sebesar $74,98 \%$.

\subsection{Pendugaan Umur Simpan dengan Pendekatan Arrhenius}

Pendugaan umur simpan dapat diketahui setelah adanya grafik penurunan mutu masing-masing suhu penyimpanan dan bahan kemasan yang ditunjukkan Gambar 3 dan Gambar 4, masingmasing grafik dicari persamaan regresi linearnya. Berdasarkan hasil perhitungan 


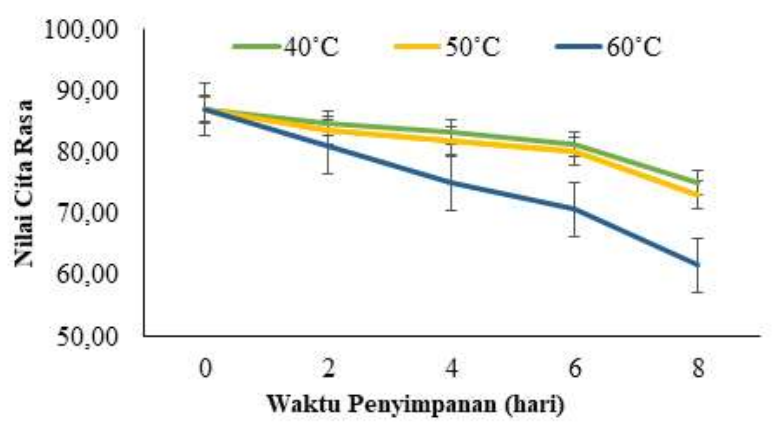

Gambar 3. Grafik Hubungan Penurunan Nilai Cita Rasa Bubuk Kopi Menggunakan Kemasan Aluminium Foil pada Suhu $40{ }^{\circ} \mathrm{C}, 50{ }^{\circ} \mathrm{C}$, dan $60^{\circ} \mathrm{C}$ (Sumber : Analisis data, 2019)

Tabel 3. Perbandingan Nilai Aluminium Foil dan Plastik (PP)

\begin{tabular}{|c|c|c|c|c|c|}
\hline Suhu & Hari Ke- & Alumunium Foil (a) & Plastik (PP) (b) & (a-b) & $(a-b)^{\wedge} 2$ \\
\hline \multirow{5}{*}{$40^{\circ} \mathrm{C}$} & 0 & 87 & 87 & 0 & 0 \\
\hline & 2 & 84,92 & 84,42 & 0,5 & 0,25 \\
\hline & 4 & 83,33 & 79,33 & 4 & 16 \\
\hline & 6 & 81,5 & 74,42 & 7,08 & 50,17 \\
\hline & 8 & 75,25 & 68,25 & 7 & 49 \\
\hline \multirow{5}{*}{$50^{\circ} \mathrm{C}$} & 0 & 87 & 87 & 0 & 0 \\
\hline & 2 & 83,75 & 83 & 0,75 & 0,56 \\
\hline & 4 & 82 & 77,67 & 4,33 & 18,78 \\
\hline & 6 & 80,33 & 72,92 & 7,42 & 55,01 \\
\hline & 8 & 73,17 & 67,33 & 5,83 & 34,03 \\
\hline \multirow{5}{*}{$60^{\circ} \mathrm{C}$} & 0 & 87 & 87 & 0 & 0 \\
\hline & 2 & 81 & 80,83 & 0,17 & 0,03 \\
\hline & 4 & 75 & 74,42 & 0,58 & 0,34 \\
\hline & 6 & 70,75 & 67 & 3,75 & 14,06 \\
\hline & 8 & 61,67 & 51 & 10,67 & 113,78 \\
\hline \multicolumn{4}{|c|}{ Jumlah } & & 352,01 \\
\hline \multicolumn{4}{|c|}{ Banyak data (n) } & & 15 \\
\hline \multicolumn{4}{|c|}{ RMSE } & & 1,25 \\
\hline
\end{tabular}

Sumber : Analisis data, 2019

didapatkan persamaan regresi linear sebagai berikut:

$$
\begin{array}{lll}
\text { Plastik } 40^{\circ} \mathrm{C} & \mathrm{y}=-4,75 x+92,933 & \mathrm{R}^{2}=0,983 \\
\text { Plastik } 50^{\circ} \mathrm{C} & \mathrm{y}=-4,9417 x+92,408 & \mathrm{R}^{2}=0,9973 \\
\text { Plastik } 60^{\circ} \mathrm{C} & \mathrm{y}=-8,5833 \mathrm{x}+97,8 & \mathrm{R}^{2}=0,9508 \\
\text { Alumunium foil } 40^{\circ} \mathrm{C} & \mathrm{y}=-2,6917 \mathrm{x}+90,475 & \mathrm{R}^{2}=0,9023 \\
\text { Alumunium foil } 50^{\circ} \mathrm{C} & \mathrm{y}=-3,1083 \mathrm{x}+90,575 & \mathrm{R}^{2}=0,911 \\
\text { Alumunium foil } 60^{\circ} \mathrm{C} & \mathrm{y}=-6,0917 \mathrm{x}+93,358 & \mathrm{R}^{2}=0,9874
\end{array}
$$

Nilai k masing-masing suhu dan jenis kemasan didapat dari nilai slope masing-masing grafiknya. Kemudian nilai ln k sebagai ordinat dan $1 / \mathrm{T}$ (suhu dalam satuan Kelvin) sebagai absis untuk mendapatkan nilai -E/R untuk setiap jenis kemasan. Data nilai T. 1/T, k, dan ln k dapat dilihat pada Tabel 4 .

Berdasarkan Gambar 5 didapatkan hubungan persamaan garis lurus antara nilai ln $\mathrm{k}$ dengan nilai $1 /$ T untuk masing-masing kemasan, yaitu:

Alumunium Foil $y=-4230,6 x+14,411 \quad R^{2}=0,8654$ Plastik (PP) $\quad y=-3057,8 x+11,237 \quad R^{2}=0,7854$

Nilai slope dari persamaan merupakan nilai-E/ R untuk masing-masing persamaan. nilai R adalah konstanta gas ( $1.986 \mathrm{kal} / \mathrm{mol} \mathrm{K})$ dan nilai energi aktivasi adalah nilai E pada persamaan sehingga 
didapatkan energi aktivasi untuk masing-masing kemasan sebagai berikut:

$$
\text { Alumunium foil: } \begin{aligned}
-\mathrm{E} / \mathrm{R} & =-4230,6 \\
\mathrm{R} & =1.986 \mathrm{kal} / \mathrm{mol} \mathrm{K} \\
\mathrm{E} & =2130,21148 \mathrm{kal} / \mathrm{mol}
\end{aligned}
$$

Plastik (PP): $\quad-E / R=-3057,8$

$$
\begin{aligned}
\mathrm{R} & =1.986 \mathrm{kal} / \mathrm{mol} \mathrm{K} \\
\mathrm{E} & =1539,677744 \mathrm{kal} / \mathrm{mol}
\end{aligned}
$$

Nilai intersep dari persamaan di atas merupakan nilai $\ln \mathrm{k} 0$, sehingga diperoleh nilai Ln $\mathrm{k} 0$ dan $\mathrm{k} 0$ dari dua jenis kemasan yang dapat dilihat pada Tabel 5. Persamaan Arrhenius dapat disusun berdasarkan nilai -E/R dan k0 yang telah diperoleh. Setelah persamaan Arrhenius untuk masing-masing jenis kemasan didapatkan, selanjutnya dapat dihitung laju penurunan cita rasa bubuk kopi kemudian disebut dengan nilai $\mathrm{K}$ berdasarkan suhu penyimpanan dan jenis kemasan.

Nilai cita rasa awal kopi sebesar 87,00 selanjutnya dilambangkan dengan huruf A0. Kopi dianggap tidak masuk kategori spesialti apabila skor cupping sudah di bawah 80 atau sudah mencapai nilai 79,75 dan nilai ini disebut dengan nilai cita rasa kritis (A). Didapatkan hasil pendugaan umur simpan kopi pada suhu penyimpanan $40^{\circ} \mathrm{C}, 50^{\circ} \mathrm{C}$, dan $60^{\circ} \mathrm{C}$ secara berturut-turut adalah 3 hari, 2 hari, dan 1,3 hari untuk kemasan aluminium foil dan 2 hari, 1,2

Tabel 4. Nilai T, $1 / \mathrm{T}$, $\mathrm{k}$ dan Ln $\mathrm{K}$

\begin{tabular}{ccccccc}
\hline Suhu & $\mathbf{T}$ & $\mathbf{1 / T}$ & $\mathbf{k}$ (plastik) & $\mathbf{k}$ (Foil) & Ln k (plastik) & Ln k (Foil) \\
\hline 40 & 313,15 & 0,0032 & 4,75 & 2,70 & 1,56 & 0,99 \\
50 & 323,15 & 0,0031 & 4,94 & 3,11 & 1,60 & 1,13 \\
60 & 333,15 & 0,0030 & 8,58 & 6,09 & 2,15 & 1,81 \\
\hline
\end{tabular}

Sumber : Analisis data, 2019

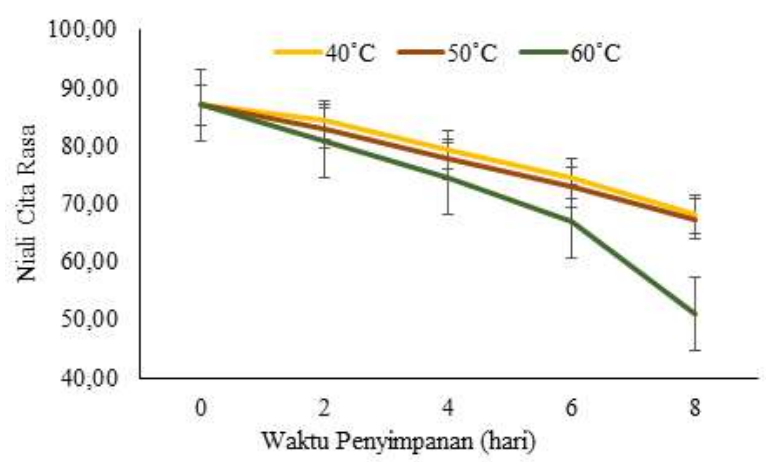

Gambar 4. Grafik Hubungan Penurunan Nilai Cita Rasa Bubuk Kopi Menggunakan Kemasan Plastik (PP) pada Suhu $40^{\circ} \mathrm{C}, 50^{\circ} \mathrm{C}$, dan $60^{\circ} \mathrm{C}$ (Sumber : Analisis data, 2019)

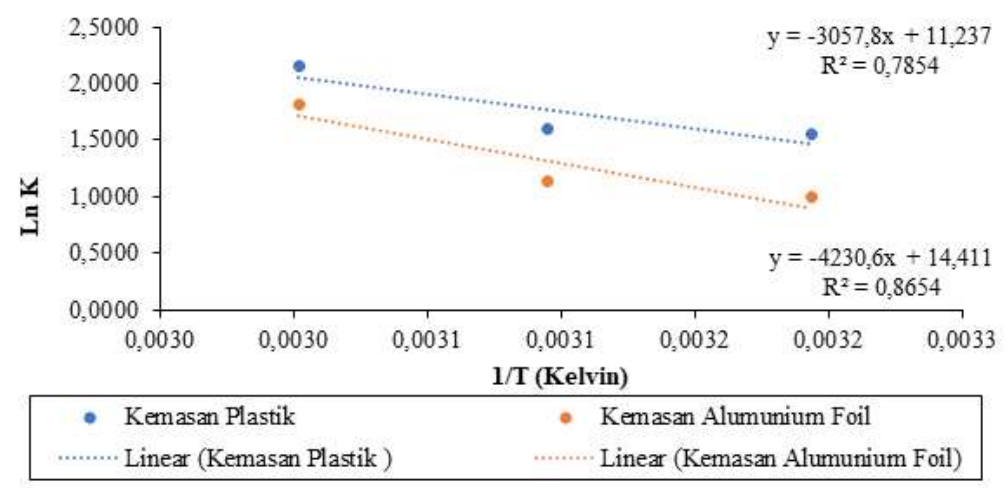

Gambar 5. Grafik Hubungan Nilai ln k dengan 1/T Bubuk Kopi Menggunakan Kemasan Aluminium Foil dan Plastik (PP)(Sumber : Analisis data, 2019) 
Tabel 5. Nilai Ln k0 dan k0 untuk Masing-masing Jenis Kemasan

\begin{tabular}{ccc}
\hline Kemasan & Ln $\mathbf{k}_{\mathbf{0}}$ & $\mathbf{k}_{\mathbf{0}}$ \\
\hline Plastik (PP) & 11,237 & 75886,94958 \\
Alumunium Foil & 14,411 & 1813918,551 \\
\hline
\end{tabular}

Sumber : Analisis data, 2019

Tabel 6. Pendugaan Umur Simpan untuk Suhu Penyimpanan $40^{\circ} \mathrm{C}, 50^{\circ} \mathrm{C}, 60^{\circ} \mathrm{C}$ dan Jenis Kemasan

\begin{tabular}{ccc}
\hline Kemasan & Suhu & Hari \\
\hline \multirow{2}{*}{ Aluminium Foil } & 40 & 3 \\
& 50 & 2 \\
& 60 & 1,3 \\
\hline \multirow{2}{*}{ Plastik (PP) } & 40 & 2 \\
& 50 & 1,2 \\
\hline
\end{tabular}

Sumber : Analisis data, 2019

Tabel 7. Pendugaan Umur Simpan untuk Suhu Penyimpanan $0^{\circ} \mathrm{C}$ Sampai $35^{\circ} \mathrm{C}$ dan Jenis Kemasan

\begin{tabular}{rcc}
\hline Kemasan & Suhu & Hari \\
\hline & 0 & 21,3 \\
& 5 & 16,1 \\
& 10 & 12,3 \\
Alumunium Foil & 15 & 9,5 \\
& 20 & 7,4 \\
& 25 & 5,8 \\
& 30 & 4,6 \\
Plastik (PP) & 35 & 3,7 \\
& 0 & 6,9 \\
& 5 & 5,7 \\
& 10 & 4,7 \\
& 15 & 3,9 \\
& 20 & 3,2 \\
& 25 & 2,7 \\
& 30 & 2,3 \\
& 35 & 1,9 \\
\hline
\end{tabular}

Sumber : Analisis data, 2019

hari, dan 1 hari untuk kemasan plastik (PP). Data lengkapnya disajikan di Tabel 6. Menurut Mulato dan Suharyanto (2015), bahwa kopi bubuk tidak dapat disimpan terlalu lama. Hal ini dikarenakan gas $\mathrm{CO}_{2}$ yang semula terjebak pada sel bubuk kopi menjadi bebas dan menguap ke udara lingkungan. Laju pelepasan gas $\mathrm{CO}_{2}$ tersebut sangat bergantung pada ukuran partikel bubuk kopi. Semakin kecil ukuran bubuk kopi maka gas $\mathrm{CO}_{2}$ yang dikeluarkan akan semakin besar. Hal ini disebabkan pada suhu tersebut aroma, rasa, warna, dan tekstur masih terjaga sehingga produk dapat bertahan lebih lama. Berdasarkan
Tabel 7, pada suhu $5^{\circ} \mathrm{C}$ sampai $35^{\circ} \mathrm{C}$ bubuk kopi spesialti dapat bertahan 3,7 sampai 16,1 hari untuk kemasan aluminium foil dan 1,9 sampai 5,7 hari untuk kemasan plastik (PP). Pendugaan umur simpan ini bukan sampai bubuk kopi tidak layak konsumsi melainkan sampai bubuk kopi tidak termasuk kategori spesialti. Umur simpan kopi spesialti sangat dipengaruhi oleh laju penurunan skor cupping (final score) selama penyimpanan, semakin rendah laju penurunan skor cupping maka umur simpannya semakin lama. 


\section{KESIMPULAN}

Berdasarkan hasil kajian perbandingan dampak penggunaan jenis kemasan pada umur simpan bubuk arabika pada penelitian ini menunjukkan bahwa bubuk kopi yang dikemas menggunakan aluminium foil memiliki laju penurunan mutu yang lebih lambat daripada kemasan plastik. Pada penyimpanan suhu $40^{\circ} \mathrm{C}$ dan $50^{\circ} \mathrm{C}$, penurunan cita rasa yang relatif stabil pada hari penyimpanan kedua, keempat, dan keenam. Namun penurunan yang signifikan terjadi pada penyimpanan hari kedelapan. Skor cupping 81,50 pada suhu $40^{\circ} \mathrm{C}$ turun menjadi 75,25 . Skor cita rasa 80,33 pada suhu $50^{\circ} \mathrm{C}$ turun menjadi 73,17 dan selanjutnya pada suhu $60^{\circ} \mathrm{C}$ penurunan skor cita rasa terjadi lebih cepat dibandingkan suhu penyimpanan $40^{\circ} \mathrm{C}$ dan $50^{\circ} \mathrm{C}$ dengan kemasan yang sama. Skor cita rasa kopi pada hari keempat sudah mencapai 75,00 sehingga skor pada hari keempat bubuk kopi sudah tidak masuk kategori kopi spesialti karena kurang dari skor cita rasa 80. Sedangkan bubuk kopi yang dikemas menggunakan plastik (PP) pada hari keempat skor cita rasa yang diperoleh dari ketiga suhu tersebut nilainya kurang dari 80 yaitu suhu $40^{\circ} \mathrm{C}(79,33), 50^{\circ} \mathrm{C}(77,67)$ dan $60^{\circ} \mathrm{C}(74,42)$. Pendugaan umur simpan menggunakan metode ASLT dengan pendekatan Arrhenius menunjukkan umur simpan bubuk kopi spesialti dengan kemasan aluminium foil yaitu 3 hari pada suhu $40^{\circ} \mathrm{C}, 2$ hari pada suhu $50^{\circ} \mathrm{C}$ dan 1,3 hari pada suhu $60^{\circ} \mathrm{C}$. Sedangkan dengan kemasan plastik (PP) umur simpannya menjadi lebih singkat yaitu 2 hari pada suhu $40^{\circ} \mathrm{C}$, 1,2 hari pada suhu $50^{\circ} \mathrm{C}$ dan 1 hari pada suhu $60^{\circ} \mathrm{C}$. Pendugaan umur simpan ini bukan sampai bubuk kopi tidak layak konsumsi tetapi sampai bubuk kopi tidak masuk kategori spesialti. Umur simpan kopi spesialti sangat dipengaruhi oleh laju penurunan skor cupping (cupping score) selama penyimpanan, semakin rendah laju penurunan skor cupping maka umur simpannya semakin lama.

\section{DAFTAR PUSTAKA}

Andayani, O. dan Agustini, S. 2019. Penentuan masa simpan kopi bubuk dalam kemasan aluminium laminated polyetilen (ALP) dan polyetilen ptalat (PET). Jurnal Dinamika Penelitian Industri, 30(2): 148-153.

Aprida, P., Suprayatmi, M., dan Hutami, R. 2017. Pendugaan umur simpan bubuk full cream yang dikemas dengan alumunium foil (AL7) atau metalized plastic (VM-PET 12). Jurnal Agroindustri Halal, 3(2), 97104.

Arpah. 2001. Penentuan Kedaluwarsa Produk Pangan. Program Studi Ilmu Pangan, Institut Pertanian Bogor.

Ati, K. dan Nursamsiyah, D.Y. 2015. Kelayakan finansial usahatani kopi arabika dan prospek pengembangannya di ketinggian sedang. Agroekonomika, 4(2): 221-234.

Cecil, R. S dan Woodroof, G. J. 1962. Long-Term Storage of Military Rations. University Georgia.

Direktorat Jenderal Perkebunan (Dirjenbun). 2017. Statistik Perkebunan Indonesia 2016-2018. Indonesia.

Hakim, F. R. 2017. Pendugaan Umur Simpan Biji Kopi Arabika Priangan Dengan Kemasan Hermetik Menggunakan Metode Arrhenius. [Skripsi]. Bogor: Institut Pertanian Bogor.

International Coffee Organization (ICO). 2019. Statistik Perdagangan. -London (GB): International Coffee Organization.

Labuza, T.P., Sporleder, T.L., Kramer, A., dan Kirk, J. 1979. Open Shelf-Life Dating of Food. Washington D.C.

Mulato, S. dan Suharyanto, E. 2015. Kopi Seduhan dan Kesehatan. Pusat Penelitian Kopi dan Kakao Indonesia.

Novita, E., Khotijah, Purbasari, D. dan Pradana, H.A. 2021. Kajian produksi bersih di Agroinudstri Kopi Wulan, Kecamatan Maesan, Kabupaten Bondowoso. Jurnal Teknik Pertanian Lampung, 10(2): 263273. 
Specialty Coffee Association of America (SCAA). 2015. Cupping Protocol. Amerika.

Sutarsi., Rhosida, E., Taruna, I. 2016. Penentuan Tingkat Sangrai Kopi Berdasarkan Sifat Fisik Kimia Menggunakan Mesin Penyangrai Tipe Rotari. Prosiding Seminar Nasional APTA, Jember 26-27 Oktober 2016.

Tarigan, E.Br., Wardiana, E. dan Supriadi, H. 2021. Pengujian umur simpan kopi arabika bubuk pada jenis kemasan dan suhu simpan yang berbeda. Jurnal Tanaman Industri dan Penyegar, 8(1): 37-48.

Wardana, S. A., Timur, A. I. M. 2018. Collaborative Filtering Recommender System Pada Virtual 3D Kelas Cendekia. Indonesian Journal of Electronics and Instrumentations System, 8(1): 73-82. 